\title{
Drivers of Permian-Triassic anoxia in the context of an Earth System Model
}

\author{
DANIEL JONATHAN BURT ${ }^{1}$, TATIANA ILYINA ${ }^{1}$ AND
}

MICHAEL JOACHIMSKI ${ }^{2}$

${ }^{1}$ Max-Planck Institute for Meteorology

${ }^{2}$ University of Erlangen-Nuremberg

Presenting Author: daniel.burt@mpimet.mpg.de

The largest mass extinction event in the Earth's history occurred at the Permian-Triassic boundary ( $252 \mathrm{Ma})$ with $90 \%$ of species going extinct within a $60 \mathrm{ka}$ interval. Climate perturbations driven by carbon emissions from Siberian Trap volcanism resulted in an extreme temperature increase as well as changes in ocean circulation and biogeochemistry, culminating in the mass extinction of marine species. Geochemical evidence suggests that large areas of the ocean became anoxic. It is still debated whether ocean anoxia followed a primary production increase, through eutrophication from enhanced weathering, or decrease, through reduced nutrient transport due to ocean stagnation. The pervasive perturbations of the Permian-Triassic climate system require a fully-coupled Earth System Model to simulate the driving processes and feedbacks. For this purpose, the Max Planck Institute Earth System Model v1.2 used in the $6^{\text {th }}$-phase of the Coupled Model Intercomparison Project is adapted for Permian-Triassic boundary simulations. The model is constrained by geochemical and palaeobiological proxy records. In this study we focus on the drivers of the extensive ocean anoxia to determine if it is the result of enhanced weathering and river discharge of nutrients or nutrient-trapping due to a stagnant ocean circulation. The model is spun-up to a best-estimate of the Late Permian climate state and perturbed through $\mathrm{CO}_{2}$ forcing to emulate the Siberian Trap emissions. First results of the Late Permian climate and oceanic biogeochemical state, as well as their sensitivities to the Permian-Triassic perturbation will be presented and discussed. 